\title{
Effect of the autonomic nervous system on cancer progression depends on the type of tumor: solid are more affected then ascitic tumors
}

\author{
${ }^{1}$ Horvathova L, ${ }^{1,2}$ Mravec B \\ ${ }^{1}$ Institute of Experimental Endocrinology, Biomedical Research Center, Slovak Academy of Sciences, Slovakia; \\ ${ }^{2}$ Institute of Physiology, Faculty of Medicine, Comenius University, Bratislava, Slovakia \\ E-mail: ueenlack@savba.sk
}

Objectives. A number of recently published studies have shown that the sympathetic nervous system may influence cancer progression. There are, however, some ambiguities about the role of the parasympathetic nerves in the modulation of growth of different tumor types. Moreover, tumor models used for investigation of the autonomic neurotransmission role in the processes related to the cancer growth and progression are mainly of the solid nature. The knowledge about the nervous system involvement in the modulation of the development and progression of malignant ascites is only fragmental. Therefore, the aim of the present article was to summarize the results of our experimental studies focused on the elucidation of the role of the autonomic nervous system in the modulation of tumor growth in animals. We are summarizing data from studies, in which not only different experimental approaches in order to influence the autonomic neurotransmission, but also different tumor models have been used.

Methods. Three different types of tumor models, namely solid rat intra-abdominal fibrosarcoma, solid murine subcutaneous melanoma, and rat ascites hepatoma, and three types of interventions have been used in order to modulate the autonomic neurotransmission, specifically chemical sympathectomy, subdiaphragmatic vagotomy, or the electric stimulation of the vagus nerve.

Results. We have proved a strong stimulatory effect of the sympathetic nerves on the development and growth in both solid tumors, rat fibrosarcoma as well as murine melanoma, and significant inhibitory impact on the survival time of tumor-bearing animals. The progression of ascites hepatoma in rats was not influenced by chemical sympathectomy. Modulation of parasympathetic signalization by vagotomy or vagal nerve stimulation does not affect fibrosarcoma and ascites hepatoma growth and survival of the tumor-bearing rats.

Conclusions. Based on the obtained data, it seems that the solid types of tumors are suitable substrate for the direct action of neurotransmitters released especially from the sympathetic nerves. In contrast, it appears that the malignant ascites are not under the direct autonomic nerves control; however, an indirect action via the immune functions modulation cannot be excluded.

Key words: sympathectomy, subdiaphragmatic vagotomy, tumor growth, vagus nerve stimulation

\footnotetext{
Corresponding author: Lubica Horvathova, PhD., Institute of Experimental Endocrinology, Biomedical Research Center, Slovak
} Academy of Sciences, Dubravska cesta 9/5779, 84505 Bratislava, Slovakia; phone: +421 232295 223; e-mail: ueenlack@savba.sk. 
During the last years, many authors have focused on the elucidation of the role of the nervous system in the regulation of biological pathways involved in the cancer growth and development of metastasis (Mancino et al. 2011; Armaiz-Pena et al. 2013; Magnon et al. 2013). These studies have greatly expanded our knowledge, especially about the sympathetic nervous system involvement in cancer biology and about the effects of locally released sympathetic neurotransmitters, on the cellular immune responses, lymphocyte traffic, inflammatory processes and cytokine production, vessel permeability, tumor-associated angiogenesis or tumor cell proliferation, invasion, and survival (Raju et al. 2007; Raju et al. 2009; Sloan et al. 2010; Lackovicova et al. 2011; Cao and During 2012; Lansdown and Rees 2012; Horvathova et al. 2015). Overall, the obtained data have strongly indicated stimulatory effect of the sympathetic nerves on the tumor progression followed by shortened survival. In contrast, only few studies have been focused on the effect of parasympathetic nervous system on the processes related to the cancer development and progression. The majority of these studies have investigated the effect of interruption of signals, conveyed by the vagus nerve, using various types of vagotomy on tumor risk and metastasis formation (Fujita et al. 1979; Tatsuta et al. 1985; Fisher et al. 1994; Lundegardh et al. 1994; Ekbom et al. 1998; Bayon Lara et al. 2001; Erin et al. 2008; Ahsberg et al. 2009). However, when comparing the effect of the sympathetic nervous system on tumor growth, more unambiguous and confused results have been obtained. Although, Gidron and co-workers (2005) have suggested inhibitory effect of the vagus nerve on the tumorigenesis, this effect has not yet been clearly demonstrated. Based on the works of Tracey and colleagues (Tracey 2002; Pavlov and Tracey 2005) about an anti-inflammatory activity of the vagus nerve and studies on the significance of the inflammatory tumor microenvironment role in the cancer progression (Croci et al. 2007; Oluwadara et al. 2010), a hypothesis that the vagus nerve might slow the tumorigenesis by suppression of the peripheral proinflammatory cytokine levels has been proposed (Gidron et al. 2005). However, there is also a contrary opinion expressed by Magnon and co-workers (2013), who, in their pioneering study, have focused on the effect of autonomic nerves on the prostate cancer progression. They have found that the formation of autonomic nerve fibers in the prostate gland may regulate prostate cancer development and dissemination in mouse models (Magnon et al. 2013). Moreover, authors have proposed an important role of the sympathetic nerves in the initial phases of the cancer development by promoting the tumor cells survival, and cholinergic fibers of the parasympathetic nervous system in tumor cell invasion, migration, and distant metastasis formation through stromal Chrm1mediated signals. According to this idea, the sympathetic fibers accumulate in the normal tissues and infiltrate the tumor edge, whereas parasympathetic fibers infiltrate tumor tissues (Magnon et al. 2013).

Based on the above-mentioned facts, it can be concluded that there is an ambiguity especially in the role of the parasympathetic branch of the autonomic nervous system in tumor development, growth, and progression. Moreover, majority of the studies investigating interactions between the nervous system and tumors have used solid tumor models (e.g. fibrosarcoma, melanoma, breast cancer, prostate cancer, gastric cancer), in which the tumor progression affecting processes, such as angiogenesis, lymphangiogenesis, and neurogenesis, can be initiated by the release of angiogenic and neurotrophic factors from the tumor cells themselves (Entschladen et al. 2006; Palm and Entschladen 2007; Voss and Entschladen 2010).

More than a decade, our Laboratory of Neurobiology is focusing on the investigation of mechanisms participating in the neural regulation of the tumor growth (neurobiology of cancer). In our experiments, we have used several experimental approaches, including sympathectomy, vagotomy, and stimulation of the vagus nerve or lesions of selected brain structures. Moreover, we have also used tumor models with different features, namely solid rat fibrosarcoma and murine melanoma, and rat ascites hepatoma.

The aim of the present article is to summarize the data of our experimental studies focusing on the elucidation of the role of the autonomic nervous system in the modulation of the tumor growth, in which we have used not only different experimental approaches, in order to influence the autonomic neurotransmission, but also different tumor models (Table 1).

\section{Used tumor models}

In our experimental studies, we have focused on the investigation of the nervous system effect on cancer biology. We have used three different types of tumor models, namely solid rat intra-abdominal fibrosarcoma, solid murine subcutaneous melanoma, and rat ascites hepatoma.

Rat intra-abdominal fibrosarcoma. Rat fibrosarcoma was induced by a single injection of $0.5 \times 10^{6}$ fibrosarcoma cells dispersed in $2 \mathrm{ml}$ of serum-free RPMI 
Table 1

Schematic overview of effects of interventions in sympathetic or parasympathetic nervous system on tumor progression (for details see text)

\begin{tabular}{|c|c|c|c|c|}
\hline \multirow{2}{*}{\multicolumn{2}{|c|}{ TUMOR MODELS }} & \multirow{2}{*}{$\begin{array}{l}\text { Sympathetic nervous system } \\
\text { intervention }\end{array}$} & \multicolumn{2}{|c|}{$\begin{array}{l}\text { Parasympathetic nervous system } \\
\text { interventions }\end{array}$} \\
\hline & & & Subdiaphragmatic vagotomy & Vagus nerve stimulation \\
\hline & $\begin{array}{l}\text { BP6-TU2 } \\
\text { fibrosarcoma } \\
\quad \text { (rat) }\end{array}$ & $\begin{array}{l}\text { - decreased tumor incidence } \\
\text { - prolonged survival of tumor- } \\
\text { bearing rats }\end{array}$ & $\begin{array}{l}\text { - no effect on tumor incidence } \\
\text { - no effect on survival of } \\
\text { tumor-bearing rats }\end{array}$ & $\begin{array}{l}\text { - no effect on tumor incidence } \\
\text { - no effect on survival of } \\
\text { tumor-bearing rats }\end{array}$ \\
\hline $\begin{array}{l}\text { Solid } \\
\text { tumors }\end{array}$ & $\begin{array}{l}\text { B16-F10 } \\
\text { melanoma } \\
\text { (murine) }\end{array}$ & $\begin{array}{l}\text { - delayed development of tumors } \\
\text { - no effect on tumor incidence } \\
\text { - ambiguous effect on size of } \\
\text { developed tumors } \\
\text { - prolonged survival of tumor- } \\
\text { bearing mice }\end{array}$ & not investigated & not investigated \\
\hline $\begin{array}{l}\text { Ascitic } \\
\text { tumor }\end{array}$ & $\begin{array}{l}\text { Yoshida AH130 } \\
\text { ascites hepatoma } \\
\text { (rat) }\end{array}$ & $\begin{array}{l}\text { - no effect on tumor incidence } \\
\text { no effect on survival of tumor- } \\
\text { bearing rats }\end{array}$ & $\begin{array}{l}\text { - no effect on tumor incidence } \\
\text { - no effect on survival of } \\
\text { tumor-bearing rats }\end{array}$ & $\begin{array}{l}\text { - no effect on tumor incidence } \\
\text { - no effect on survival of } \\
\text { tumor-bearing rats }\end{array}$ \\
\hline
\end{tabular}

1640 medium. The rat BP6-TU2 fibrosarcoma cells used were routinely cultured in RPMI 1640 medium containing $10 \%$ fetal calf serum supplemented with antibiotics, namely kanamycin and streptomycin. Tumor cells were injected to the male Wistar rats (AnLab, Prague, Czech Republic) intraperitoneally (into the left bottom quadrant of the abdominal cavity) without anesthesia. Control rats were exposed to the same volume of the serum-free medium.

Murine subcutaneous melanoma. Murine melanoma was induced by a single dose of $3 \times 10^{3}$ tumor cells in $0.1 \mathrm{ml}$ of RPMI 1640 medium per animal without anesthesia. A B16-F10 melanoma cell suspension was injected subcutaneously (into the subcutaneous space at the level of the thoraco-lumbar spinal cord). Before tumor cells inoculation, back of animals was shaven and disinfected. Experiments were performed on 3 months-old male mice (strain C57BL/6J) that were bred at the Institute of Experimental Endocrinology, Slovak Academy of Science. Control mice were injected only with serum-free medium.

Rat ascites hepatoma. Rat ascitic hepatoma was induced using a model of one-off injection of $5 \times 10^{6}$ Yoshida AH-130 ascites hepatoma cells in a total volume of $2 \mathrm{ml}$ of phosphate solution ( $\mathrm{pH} 7.3$ ) per rat without anesthesia. Tumor cell suspension was injected intraperitoneally (into the left bottom quadrant of the abdominal cavity) into syngeneic male Wistar rats (AnLab, Prague, Czech Republic). Animals injected by vehicle without tumor cells served as control.

\section{Interventions and their effects on tumor growth}

Chemical sympathectomy. Chemical sympathectomy was performed 7 days before the tumor cells application in conscious animals by intraperitoneal injection of 6-hydroxydopamine hydrobromide (6-OHDA; $100 \mathrm{mg} / \mathrm{kg}$ of body weight, Sigma-Aldrich, Germany) over 2 consecutive days. The 6-OHDA was dissolved in sterile saline containing $0.1 \%$ of the antioxidant ascorbic acid (Sigma-Aldrich, Germany). This dose has been shown to induce destruction of the sympathetic nerve endings after 3-5 days and this effect lasted for at least 21 days in spleen (Kruszewska et al. 1995). An efficiency of the sympathectomy was confirmed immediately after application of 6-OHDA by presence of eyelids ptosis in the sympathectomized animals (Claude Bernard-Horner's syndrome) and blood in urine indicating the destruction of the sympathetic nerve endings in the urinary tract. Moreover, 7 days after 6-OHDA treatment, we found decreased levels of norepinephrine in the spleen (Horvathova et al. 2015; Horvathova et al. 2016a). Control animals to 6-OHDA groups were intraperitoneally injected with vehicle (sterile saline containing $0.1 \%$ of the antioxidant ascorbic acid).

The incidence of the intra-abdominal fibrosarcoma in Wistar rats was after 6-OHDA-induced sympathectomy significantly reduced. Tumor masses were found in the abdominal cavity of $87 \%$ animals with an intact sympathetic nervous system injected with BP6-TU2 tumor cells compared to $61 \%$ rats in 
the group that received 6-OHDA before injection of BP6-TU2 cells. Moreover, a significantly prolonged survival of sympathectomized tumor-bearing rats in comparison with animals that did not receive 6-OHDA pretreatment was also observed. Median survival of tumor-bearing rats with intact sympathetic nerves was 39.5 days and of tumor-bearing animals treated with 6-OHDA was 55 days (Lackovicova et al. 2011).

In animals injected subcutaneously with the murine melanoma cells, similar effect of sympathectomy on tumor growth and survival was observed, as well. Here, we noticed significantly delayed development of tumors in the sympathectomized mice in comparison with the mice that were not treated with 6-OHDA. Moreover, we have shown that chemical sympathectomy also significantly prolonged the mice survival. Median survival of melanoma-bearing mice was without 6-OHDA treatment 29 days and after 6-OHDA treatment 34 days. However, there was no difference in the incidence of melanoma in mice with intact sympathetic nerves $(100 \%$ incidence of tumors - all animals injected with melanoma cells had developed tumor) and sympathectomized mice (two animals from all injected with melanoma cells did not develop tumor that represents $92.6 \%$ (Horvathova et al. 2016b). Moreover, the effect of the chemical sympathectomy on the melanoma progression was assessed also by weighting of developed melanoma mass. In mice sacrificed in earlier stage of melanoma growth (on the 20 $0^{\text {th }}$ day after B16-F10 melanoma cells injection), 6-OHDA treatment resulted in a significant reduction of the tumor mass when compared to animals with the intact sympathetic nerves (Horvathova et al. 2016a). Interestingly, in survival study we found that weight of the developed melanoma tissue in sympathectomized animals was significantly increased in comparison with vehicle group animals (Horvathova et al. 2016b).

In the contrary to the above-mentioned findings, the chemical sympathectomy did not affect the incidence of the ascites hepatoma in Wistar rats. We found ascites in the abdominal cavity of $80.9 \%$ animals with an intact sympathetic nervous system and injected with tumor cells compared to $80 \%$ rats in the group that received 6-OHDA before injection of the tumor cells. Similarly, sympathectomy did not affect survival of tumor-bearing rats in comparison with the tumor-bearing animals with intact sympathetic nervous system. Median survival of tumorbearing rats with intact sympathetic nerves was 17 days and of the tumor-bearing animals underwent sympathectomy 18 days (Horvathova et al. 2015).
Subdiaphragmatic vagotomy. Subdiaphragmatic vagotomy was performed 14 days before the tumor cells application to rats weighing $225 \pm 25$ g. Prior to surgery, all the animals were food deprived overnight. Rats were anesthetized with an intramuscular injection of a mixture of ketamine (Narkamon $5 \%-1.2 \mathrm{ml} / \mathrm{kg}$ body weight, Spofa, Czech Republic) and xylazine (Rometar $2 \%-0.4 \mathrm{ml} / \mathrm{kg}$ body weight, Spofa, Czech Republic). The vagal trunks were isolated via upper midline laparotomy, following which the ventral and dorsal branches of the subdiaphragmatic vagus nerve were cut. In sham-operated rats, the vagal trunks were similarly exposed but the vagal branches were not cut. To avoid the gastrointestinal complications of vagotomy (e.g. gastrostasis), all the vagotomized and sham operated rats were fed with a liquid nutrition (Fresubin, Germany) for 7 days following surgery.

This surgical intervention, carried out in order to reduce signals conveyed by the vagus nerve, was performed only in rats that were subsequently injected with either fibrosarcoma or hepatoma cells.

Incidence of the rat intra-abdominal fibrosarcoma in Wistar rats was slightly reduced by subdiaphragmatic vagotomy in comparison with shamoperated animals. We found tumor masses in the abdominal cavity of $29.2 \%$ vagotomized rats. In contrast, we detected tumors in $45.8 \%$ sham-operated animals. However, we did not find any significant difference in the survival of vagotomized rats (median survival 57 days) versus sham-operated rats (median survival 51 days) (Mikova et al. 2015).

Subdiaphragmatic vagotomy affected neither incidence of the ascites hepatoma in Wistar rats nor survival of these animals. There were no differences in the tumor incidence between the animals underwent vagotomy or sham operation. The presence of ascites was confirmed by $83.3 \%$ in sham-operated rats in comparison with $58.3 \%$ animals with subdiaphragmatic vagotomy. No marked effect of subdiaphragmatic vagotomy was observed also in survival of the tumor-bearing rats. Median survival of shamoperated rats was 19 days and 19.5 days of animals underwent to vagotomy (unpublished data).

Electric stimulation of the vagus nerve (VNS). Implantation of stimulators was performed 14 days before tumor cells application in rats weighing 200-250 g. Rats were implanted with VNS or sham devices [VNS micropulse - model 103 by Cyberonics Inc. (USA) with the following dimensions: $7 \times 42 \times 32 \mathrm{~mm}$, oval shape; weight $15.6 \mathrm{~g}]$ under anesthesia (an intramuscular injection of a mixture of ketamine and xylazine) and aseptic conditions. The 
body of the stimulator was implanted subcutaneously into the animal's back. The connecting cable with electrodes was lead under the skin with the active ends of electrodes placed around the left cervical portion of the vagus nerve. Sham animals underwent the same surgical procedure with implantation of connecting cable and electrodes, but with a sham device of the same size and weight used in place of the functional stimulator. The devices were set up using NeuroCybernetic Prosthesis hand-held computer and programming wand (Cyberonics Inc.) and the impedance of electrodes was measured to confirm the presence of an appropriate contact between the nerve and the stimulating coil. Activation of functional VNS was performed three days after the tumor cells injection. The stimulators were turned on and programmed as following: $30 \mathrm{~s}$ on and $5 \mathrm{~min}$ off in continuous cycles, at a frequency of $20 \mathrm{~Hz}$, pulse width of $500 \mu \mathrm{s}$, with an intensity of $0.25 \mathrm{~mA}$.

This surgical intervention carried out in order to stimulate a cholinergic anti-inflammatory pathway and to reduce cancer-related inflammation was performed only in rats, which were subsequently injected with either fibrosarcoma or hepatoma cells.

The electric stimulation of the vagus nerve did not influence the incidence of the intra-abdominal fibrosarcoma in Wistar rats. After 94 days of a continual vagal stimulation, tumors developed in $55 \%$ of animals from VNS group versus $80 \%$ of group of rats with sham devices. Survival of tumor-bearing animals was determined by the number of rats surviving up to 94 days after VNS activation. Similarly, vagal stimulation did not affect survival of rats injected with fibrosarcoma cells (median survival 42 days) in comparison to rats with sham devices (median survival 46 days) (Mikova et al. 2015).

In the case of the ascites hepatoma, 29 days lasting continuous stimulation of the vagus nerve also did not affect the tumor incidence in Wistar rats. The presence of ascites was confirmed in $60 \%$ of the experimental animals from VNS group. In the group of the tumor-bearing rats with sham devices, ascites was found in $71.4 \%$ animals. VNS had also no impact on the survival of the tumor-bearing animals. Median survival of rats with sham devices was 19 days and of animals from VNS group 20 days (unpublished data).

\section{Discussion}

A number of recently published studies have indicated that the nervous system may influence the progression of cancer by inhibiting theimmune system functions, affecting the metabolic reprogramming of tumor cells, stimulating angiogenesis, or affecting the interactions between the tumor cells and other cellular and structural components of the tumor microenvironment (Shang 2007; Sloan et al. 2010; Park et al. 2011; Shi et al. 2013; Calvani et al. 2015; Chang et al. 2015). Although, there are ambiguities especially about the role of the parasympathetic nerves in the growth of different types of tumors, generally, it has been shown that autonomic neurotransmitters may stimulate the cancer cell growth through the activation of the cancer-related signaling pathways (Jobling et al. 2015). Moreover, two significant neurobiological studies in prostate and gastric cancer (Magnon et al. 2013; Zhao et al. 2014) have revealed that the sympathetic and parasympathetic nerves are significantly involved in all phases of the prostate cancer development in the mouse and surgical or pharmacologic denervation of the mouse stomach strongly reduces tumor incidence and progression of the gastric cancer. Although, it is known that the sympathetic and parasympathetic nervous systems may affect the functions of the innervated tissues and organs in opposite way, the above-mentioned studies have suggested that in cancer they act complementary to each other; sympathetic nerves stimulate early phases of tumor growth and parasympathetic ones activate the late metastatic process (Jobling et al. 2015). Using several experimental approaches (surgical as well as pharmacological), we have investigated the participation of sympathetic and parasympathetic nerves in cancer development and progression. The results obtained from our experimental studies have supported the stimulatory role of the sympathetic neurotransmission in the case of an intra-abdominal rat fibrosarcoma (Lackovicova et al. 2011) and subcutaneous murine melanoma (Horvathova et al. 2016b). However, the involvement of the parasympathetic nerves in growth of rat intra-abdominal fibrosarcoma has not been observed (Mikova et al. 2015). It is necessary to note that all the tumor models used for the investigation of the autonomic neurotransmission role in the processes related to the cancer growth and progression are solid, e.g. prostate cancer, gastric cancer, fibrosarcoma, melanoma, tongue cancer, or breast cancer (Raju et al. 2009; Lackovicova et al. 2011; Erin et al. 2012; Magnon et al. 2013; Zhao et al. 2014; Calvani et al. 2015; Mikova et al. 2015). It may be assumed that just the solid nature of these tumors will make them the suitable substrate for the direct action of neurotransmitters released from the autonomic nerves.

Mancino and colleagues (2011) have proposed that tumor development, like normal organ homeostasis, 
should be considered as a result of continuous bidirectional interactions between the tumor cells and their surrounding microenvironment. It is known that the angiogenesis, lymphangiogenesis, as well as neurogenesis are essential for tissue homeostasis in the healthy individuals (Mancino et al. 2011).

The role of the blood and lymphatic vessels in the malignant progression of the cancer have been well described (Bergers and Benjamin 2003; Hillen and Griffioen 2007; Sundar and Ganesan 2007), but cancer-related formation of nerves or axons has not been supposed for a long time. However, recent evidence has led to the description of a novel biological phenomenon. It has been proved that the solid tumors, like another integrated tissues, are able to release neurotrophic factors that regulate the survival, growth, and differentiation of the nerve cells and so initiate their own innervation (Palm and Entschladen 2007; Olar et al. 2014). This infiltration of the tumor microenvironment by nerves has been termed as tumor neoneurogenesis or axonogenesis (Entschladen et al. 2006). The experimental data have suggested that these nerves may play an active role in the cancer progression and enable the brain influence this process directly by nervous pathways (Shi et al. 2013). However, the detailed knowledge of the role of nerves in the tumors is obscure. Initially, it was thought that the role of the nerve fibers in the tumors is only mechanical and existing nerves will serve as mechanical "paths" that allow the migration of the invading cells and contribute to the tumor progression (Liebig et al. 2009; Jobling et al. 2015). This process has been called as a perineural invasion and has been correlated with a poorer prognosis in various human tumors (Anderson et al. 1998; Bauman and McVary 2013). During perineural invasion, the tumor cells migrate along nerves, but nerves themselves are "passive" components in this process (Jobling et al. 2015). However, accumulating evidence have suggested that the nerves found in tumors are not passive, but in fact they are functionally relevant, modulating a complex of mediators network related to the tumor microenvironment (Mancino et al. 2011). It seems that nerve fibers may infiltrate into the tumor tissue stimulating the growth and dissemination of cancer cells and reciprocally, the tumor cells may drive the nerve outgrowth in a cross-talk that contributes to the tumor progression (Jobling et al. 2015). In support of this, it is known that the neurotransmitters released form nerve endings may modulate the biological behaviors of both tumor and stromal cells by binding to the related receptors expressed by these cells
(Entschladen et al. 2002; Moody et al. 2003; Soll et al. 2010; Mayordomo et al. 2012; Moreno-Smith et al. 2013). Therefore, local microenvironment and multiple physiologic processes of the tumor development may be controlled by nerves and the brain (Shi et al. 2013).

To elucidate and extend the knowledge about the mechanisms responsible for modulatory effects of the autonomic nervous system on the development and progression of solid tumors further investigations are necessary. Importantly, there are no data related to the role of nervous system in non-solid tumors of ascitic type. Therefore, we have started to investigate this. We have performed series of experiments in order to determine whether reduced or exaggerated autonomic neurotransmission has the same impact on the development and progression of malignant ascites as in the case of the solid tumors. However, we have found that the surgical and pharmacological experimental approaches used (chemical sympathectomy, subdiaphragmatic vagotomy, or electrical stimulation of the vagus nerve) had no effect on the development and progression of the ascites hepatoma or on the survival of asictes-bearing animals. We have supposed that the ascitic nature of this type of tumor does not allow forming blood and lymphatic vessels and nerves, which play a significant role in the tumor progression.

The presence of malignant ascites is a common and distressing complication of the human abdominal cancer with abdominal distension and changes in abdominal girth as the classic symptoms (Stanojevic et al. 2004). Usually, malignant ascites is a sign of the peritoneal carcinomatosis (malignancies including ovarian, colorectal, pancreatic and uterine; extraabdominal tumors originating from lymphoma, lung and breast; and a small number of unknown primary tumors) and indicates the presence of malignant cells in the peritoneal cavity. Importantly, it represents a significant marker of a poor prognosis (Sangisetty and Miner 2012).

The pathogenesis of the malignant ascites formation is a complex multifactorial process. It has been postulated that the major factors in the malignant ascites formation are the altered vascular permeability and the obstructed lymphatic drainage (HolmNielsen 1953; Sangisetty and Miner 2012). It has been shown that vessels of the peritoneal lining in experimental animals with tumor ascites were significantly more permeable, due to the presence of a permeability factor found only in the tumor ascites (Senger et al. 1983). Particularly, the combination of an impaired lymphatic drainage and increased vascular 
permeability presents the mechanism responsible for the fluid and protein accumulation in the intraperitoneal space. These processes are intertwined, allowing for the net filtration that overwhelms the ability of the lymphatic system to drain the peritoneal space, particularly when obstructed by increasing tumor burden (Sangisetty and Miner 2012). The quality of the fluid in patients with malignancy related ascites is, due to peritoneal carcinomatosis, distinctive with positive cytology of malignant cells, large number of white blood cells, higher lactate dehydrogenase level, high ascitic fluid protein concentrations (it indicates an alteration in vascular permeability that allows accumulation of large molecules in the intraperitoneal space), and low serum-ascites albumin gradient (Runyon et al. 1988; Bjelakovic et al. 2001; Sangisetty and Miner 2012). Hence, the ascitic fluid may be used for various biochemical, cytological, and microbiological analysis that can help in the differential diagnosis of ascites (Stanojevic et al. 2004).

The use especially of the mouse ascites tumors, as an experimental tool in cancer research, is wellestablished (Siegler and Koprowska 1962). In our animal experiments, the rat Yoshida AH-130 ascites hepatoma was used for study of interactions between the nervous system and cancer. This type of ascites was originally prepared by conversion of the aminoazo-dye-induced hepatoma of the rat into the ascitic form and it is similar in all aspects to other types of ascites tumors of various derivations (Yoshida 1956). It has widely been used in experimental studies investigating the cancer anorexia-cachexia syndrome, since in the host the implantation of these tumor cells leads to a very fast and progressive body weight loss associated with both fat and skeletal muscle wasting, reduced food intake accompanied by anorexia in the terminal state, and protein and lipid hypercatabolism (Tessitore et al. 1987; Costelli et al. 1999). It is a highly cachectic rat tumor of rapid growth and poorly differentiated cells (Marzabal et al. 1993). It is necessary to note that the animals inoculated with the ascites hepatoma present beside accumulation of the ascitic fluid ample solid tumors on the peritoneal surface, which may invade into the surrounding tissues, and are identified easily as hepatoma on histological sections (Yoshida 1956). Distant metastases of the tumor can occur rarely due to the relatively short duration of the tumor-bearing animals' life (Yoshida 1956). In our experiments, we have never found any metastases formation.

We have proposed that one of the significant pathways that may enable interactions between the nervous system and tumor in form of ascites is neural regulation of the immune system that has the capacity to recognize tumor-associated antigens and develop antigen-specific humoral and cell mediated responses to these targets (Giuntoli et al. 2009). It is now well established that nervous and immune systems exhibit intricate bi-directional interactions to facilitate the fine control required maintaining homeostasis of the body (Karimi et al. 2010). Neuroanatomical and neuroendocrine studies have demonstrated a role for the nervous system in regulating immune function via the hypothalamic-pituitary-adrenal axis and the autonomic nervous system (Meltzer et al. 1997). Traditionally, investigations are focused on the sympathetic control of the immune response. The sympathetic arm of the autonomic nervous system may play the major role in the immune function regulation via the direct sympathetic innervation of all immune organs (Nance and Sanders 2007). However, a number of more recent studies have highlighted the role of the efferent parasympathetic system and in particular a role for the vagus nerve in immunoregulation through cholinergic signaling at the $a 7$ subtype of nicotinic receptor, even if there are several open questions regarding the mechanisms (Borovikova et al. 2000; Tracey 2002; Gidron et al. 2005; Pavlov and Tracey 2005; Wang et al. 2007). In our experiments, manipulation with sympathetic or parasympathetic nerves does not affect the ascites hepatoma development and progression in Wistar rats. However, reduced sympathetic neurotransmission led to an increased prognostic marker of inflammation, neutrophil-to-lymphocyte and leukocyteto-lymphocyte ratios, and increased plasma levels of proinflammatory cytokine tumor necrosis factor alpha in tumor-bearing rats (Horvathova et al. 2015). Therefore, it appears that by affecting the autonomic nerves, functional alterations in the immune system components may occur, but in the case of the ascites tumor, these had no significant effect on the cancer progression. Therefore, on the base of abovementioned findings, it seems that the direct communication between tumor cells and nerves is necessary for the effective modulatory effects of nervous system on the cancer progression.

\section{Conclusion}

In summary, our data indicate that based on the tumor type, significant differences in the effect of the nervous system on the tumor growth and development of metastases, may exist. Especially, the sympathetic nerves may markedly affect the progression of different solid tumors, regardless of the site of their 
growth (intraperitoneal vs. subcutaneous). However, the observed paradigm was not showed in the case of the ascites hepatoma. It seems that crucial role in these differences may play the solid tumors by the direct sympathetic innervations supply, whereas released neurotransmitters may modulate the behavior of the tumor and other stromal cells by paracrine manner. On the other hand, we did not reveal significant role of the parasympathetic nerves in the tumor progression regardless of the place its growth.

\section{References}

Ahsberg K, Olsson H, Stael von Holstein C. Increased mortality in prostate carcinoma and smoking-related disease after parietal cell vagotomy: a long-term follow-up study. Scand J Gastroenterol 44, 947-951, 2009.

Anderson PR, Hanlon AL, Patchefsky A, Al-Saleem T, Hanks GE. Perineural invasion and Gleason 7-10 tumors predict increased failure in prostate cancer patients with pretreatment PSA $<10 \mathrm{ng} / \mathrm{ml}$ treated with conformal external beam radiation therapy. Int J Radiat Oncol Biol Phys 41, 1087-1092, 1998.

Armaiz-Pena GN, Cole SW, Lutgendorf SK, Sood AK. Neuroendocrine influences on cancer progression. Brain Behav Immun 30 Suppl, S19-25, 2013.

Bauman J, McVary K. Autonomic nerve development contributes to prostate cancer progression. Asian J Androl 15, 713-714, 2013.

Bayon Lara AM, Landa Garcia I, Alcalde Escribano J, Rodriguez Dapena S, Ortega Medina L, Balibrea Cantero JL. Colonic carcinogenesis in vagotomyzed rats. Rev Esp Enferm Dig 93, 576-586, 2001.

Bergers G, Benjamin LE. Tumorigenesis and the angiogenic switch. Nat Rev Cancer 3, 401-410, 2003.

Bjelakovic G, Tasic T, Stamenkovic I, Stojkovic M, Katic V, Otasinovic M, Bjelakovic G. Biochemical, cytological and microbiological characteristics of the cirrhotic, malignant and "mixed" ascites. Arch Oncol 9, 95-101, 2001.

Borovikova LV, Ivanova S, Nardi D, Zhang M, Yang H, Ombrellino M, Tracey KJ. Role of vagus nerve signaling in CNI-1493-mediated suppression of acute inflammation. Auton Neurosci 85, 141-147, 2000.

Calvani M, Pelon F, Comito G, Taddei ML, Moretti S, Innocenti S, Nassini R, Gerlini G, Borgognoni L, Bambi F, Giannoni E, Filippi L, Chiarugi P. Norepinephrine promotes tumor microenvironment reactivity through beta3-adrenoreceptors during melanoma progression. Oncotarget 6, 4615-4632, 2015.

Cao L, During MJ. What is the brain-cancer connection? Annu Rev Neurosci 35, 331-345, 2012.

Costelli P, Tessitore L, Batetta B, Mulas MF, Spano O, Pani P, Baccino FM, Dessi S. Alterations of lipid and cholesterol metabolism in cachectic tumor-bearing rats are prevented by insulin. J Nutr 129, 700-706, 1999.

Croci DO, Zacarias Fluck MF, Rico MJ, Matar P, Rabinovich GA, Scharovsky OG. Dynamic cross-talk between tumor and immune cells in orchestrating the immunosuppressive network at the tumor microenvironment. Cancer Immunol Immunother 56, 1687-1700, 2007.

Ekbom A, Lundegardh G, McLaughlin JK, Nyren O. Relation of vagotomy to subsequent risk of lung cancer: population based cohort study. BMJ 316, 518-519, 1998.

Entschladen F, Lang K, Drell TL, Joseph J, Zaenker KS. Neurotransmitters are regulators for the migration of tumor cells and leukocytes. Cancer Immunol Immunother 51, 467-482, 2002.

Entschladen F, Palm D, Lang K, Drell TLt, Zaenker KS. Neoneurogenesis: tumors may initiate their own innervation by the release of neurotrophic factors in analogy to lymphangiogenesis and neoangiogenesis. Med Hypotheses 67, 33-35, 2006.

Erin N, Akdas Barkan G, Harms JF, Clawson GA. Vagotomy enhances experimental metastases of 4THMpc breast cancer cells and alters substance P level. Regul Pept 151, 35-42, 2008.

Erin N, Duymus O, Ozturk S, Demir N. Activation of vagus nerve by semapimod alters substance P levels and decreases breast cancer metastasis. Regul Pept 179, 101-108, 2012.

Fisher SG, Davis F, Nelson R, Weber L, Haenszel W. Large bowel cancer following gastric surgery for benign disease: a cohort study. Am J Epidemiol 139, 684-692, 1994.

Fujita M, Takami M, Usugane M, Nampei S, Taguchi T. Enhancement of gastric carcinogenesis in dogs given Nmethyl-N'-nitro-N-nitrosoguanidine following vagotomy. Cancer Res 39, 811-816, 1979.

Gidron Y, Perry H, Glennie M. Does the vagus nerve inform the brain about preclinical tumours and modulate them? Lancet Oncol 6, 245-248, 2005.

Giuntoli RL, 2nd, Webb TJ, Zoso A, Rogers O, Diaz-Montes TP, Bristow RE, Oelke M. Ovarian cancer-associated ascites demonstrates altered immune environment: implications for antitumor immunity. Anticancer Res $29,2875-2884,2009$. 
Hillen F, Griffioen AW. Tumour vascularization: sprouting angiogenesis and beyond. Cancer Metastasis Rev 26, 489-502, 2007.

Holm-Nielsen P. Pathogenesis of ascites in peritoneal carcinomatosis. Acta Pathol Microbiol Scand 33, 10-21, 1953.

Horvathova L, Tillinger A, Sivakova I, Mikova L, Mravec B, Bucova M. Chemical sympathectomy increases neutrophil-to-lymphocyte ratio in tumor-bearing rats but does not influence cancer progression. J Neuroimmunol 278, 255-261, 2015.

Horvathova L, Padova A, Tillinger A, Osacka J, Bizik J, Mravec B. Sympathectomy reduces tumor weight and affects expression of tumor-related genes in melanoma tissue in the mouse. Stress 19, 528-534, 2016a.

Horvathova L, Tillinger A, Padova A, Mravec B. Sympathectomized tumor-bearing mice survive longer but develop bigger melanomas. Endocrine Regulations 50, 207-214, $2016 \mathrm{~b}$.

Chang A, Kim-Fuchs C, Le CP, Hollande F, Sloan EK. Neural Regulation of Pancreatic Cancer: A Novel Target for Intervention. Cancers (Basel) 7, 1292-1312, 2015.

Jobling P, Pundavela J, Oliveira SM, Roselli S, Walker MM, Hondermarck H. Nerve-Cancer Cell Cross-talk: A Novel Promoter of Tumor Progression. Cancer Res 75, 1777-1781, 2015.

Karimi K, Bienenstock J, Wang L, Forsythe P. The vagus nerve modulates CD4+ T cell activity. Brain Behav Immun 24, 316-323, 2010.

Kruszewska B, Felten SY, Moynihan JA. Alterations in cytokine and antibody production following chemical sympathectomy in two strains of mice. J Immunol 155, 4613-4620, 1995.

Lackovicova L, Banovska L, Bundzikova J, Janega P, Bizik J, Kiss A, Mravec B. Chemical sympathectomy suppresses fibrosarcoma development and improves survival of tumor-bearing rats. Neoplasma 58, 424-429, 2011.

Lansdown A, Rees DA. The sympathetic nervous system in polycystic ovary syndrome: a novel therapeutic target? Clin Endocrinol (Oxf) 77, 791-801, 2012.

Liebig C, Ayala G, Wilks JA, Berger DH, Albo D. Perineural invasion in cancer: a review of the literature. Cancer 115, 3379-3391, 2009.

Lundegardh G, Ekbom A, McLaughlin JK, Nyren O. Gastric cancer risk after vagotomy. Gut 35, 946-949, 1994.

Magnon C, Hall SJ, Lin J, Xue X, Gerber L, Freedland SJ, Frenette PS. Autonomic nerve development contributes to prostate cancer progression. Science 341, 1236361, 2013.

Mancino M, Ametller E, Gascon P, Almendro V. The neuronal influence on tumor progression. Biochim Biophys Acta 1816, 105-118, 2011.

Marzabal M, Garcia-Martinez C, Comas J, Lopez-Soriano FJ, Argiles JM. A flow cytometric study of the rat Yoshida AH-130 ascites hepatoma. Cancer Lett 72, 169-173, 1993.

Mayordomo C, Garcia-Recio S, Ametller E, Fernandez-Nogueira P, Pastor-Arroyo EM, Vinyals L, Casas I, Gascon P, Almendro V. Targeting of substance P induces cancer cell death and decreases the steady state of EGFR and Her2. J Cell Physiol 227, 1358-1366, 2012.

Meltzer JC, Grimm PC, Greenberg AH, Nance DM. Enhanced immunohistochemical detection of autonomic nerve fibers, cytokines and inducible nitric oxide synthase by light and fluorescent microscopy in rat spleen. J Histochem Cytochem 45, 599-610, 1997.

Mikova L, Horvathova L, Ondicova K, Tillinger A, Vannucci LE, Bizik J, Gidron Y, Mravec B. Ambiguous effect of signals transmitted by the vagus nerve on fibrosarcoma incidence and survival of tumor-bearing rats. Neurosci Lett 593, 90-94, 2015.

Moody TW, Hill JM, Jensen RT. VIP as a trophic factor in the CNS and cancer cells. Peptides 24, 163-177, 2003.

Moreno-Smith M, Lee SJ, Lu C, Nagaraja AS, He G, Rupaimoole R, Han HD, Jennings NB, Roh JW, Nishimura M, Kang Y, Allen JK, Armaiz GN, Matsuo K, Shahzad MM, Bottsford-Miller J, Langley RR, Cole SW, Lutgendorf SK, Siddik ZH, Sood AK. Biologic effects of dopamine on tumor vasculature in ovarian carcinoma. Neoplasia 15, 502-510, 2013.

Nance DM, Sanders VM. Autonomic innervation and regulation of the immune system (1987-2007). Brain Behav Immun 21, 736-745, 2007.

Olar A, He D, Florentin D, Ding Y, Ayala G. Biologic correlates and significance of axonogenesis in prostate cancer. Hum Pathol 45, 1358-1364, 2014.

Oluwadara O, Giacomelli L, Brant X, Christensen R, Avezova R, Kossan G, Chiappelli F. The role of the microenvironment in tumor immune surveillance. Bioinformation 5, 285-290, 2010.

Palm D, Entschladen F. Neoneurogenesis and the neuro-neoplastic synapse. Prog Exp Tumor Res 39, 91-98, 2007.

Park SY, Kang JH, Jeong KJ, Lee J, Han JW, Choi WS, Kim YK, Kang J, Park CG, Lee HY. Norepinephrine induces VEGF expression and angiogenesis by a hypoxia-inducible factor-1alpha protein-dependent mechanism. Int J Cancer 128, 2306-2316, 2011. 
Pavlov VA, Tracey KJ. The cholinergic anti-inflammatory pathway. Brain Behav Immun 19, 493-499, 2005.

Raju B, Haug SR, Ibrahim SO, Heyeraas KJ. Sympathectomy decreases size and invasiveness of tongue cancer in rats. Neuroscience 149, 715-725, 2007.

Raju B, Hultstrom M, Haug SR, Ibrahim SO, Heyeraas KJ. Sympathectomy suppresses tumor growth and alters geneexpression profiles in rat tongue cancer. Eur J Oral Sci 117, 351-361, 2009.

Runyon BA, Hoefs JC, Morgan TR. Ascitic fluid analysis in malignancy-related ascites. Hepatology 8, 1104-1109, 1988.

Sangisetty SL, Miner TJ. Malignant ascites: A review of prognostic factors, pathophysiology and therapeutic measures. World J Gastrointest Surg 4, 87-95, 2012.

Senger DR, Galli SJ, Dvorak AM, Perruzzi CA, Harvey VS, Dvorak HF. Tumor cells secrete a vascular permeability factor that promotes accumulation of ascites fluid. Science 219, 983-985, 1983.

Shang Y. Hormones and cancer. Cell Res 17, 277-279, 2007.

Shi M, Liu D, Yang Z, Guo N. Central and peripheral nervous systems: master controllers in cancer metastasis. Cancer Metastasis Rev 32, 603-621, 2013.

Siegler R, Koprowska I. Mechanism of an ascites tumor formation. Cancer Res 22, 12733, 1962.

Sloan EK, Priceman SJ, Cox BF, Yu S, Pimentel MA, Tangkanangnukul V, Arevalo JM, Morizono K, Karanikolas BD, Wu L, Sood AK, Cole SW. The sympathetic nervous system induces a metastatic switch in primary breast cancer. Cancer Res 70, 7042-7052, 2010.

Soll C, Jang JH, Riener MO, Moritz W, Wild PJ, Graf R, Clavien PA. Serotonin promotes tumor growth in human hepatocellular cancer. Hepatology 51, 1244-1254, 2010.

Stanojevic Z, Rancic G, Radic S, Potic-Zecevic N, Dordevic B, Markovic M, Todorovska I. Pathogenesis of malignant ascites in ovarian cancer patients. Arch Oncol 12, 115-118, 2004.

Sundar SS, Ganesan TS. Role of lymphangiogenesis in cancer. J Clin Oncol 25, 4298-4307, 2007.

Tatsuta M, Yamamura H, Iishi H, Ichii M, Noguchi S, Baba M, Taniguchi H. Promotion by vagotomy of gastric carcinogenesis induced by N-methyl-N'-nitro-N-nitrosoguanidine in Wistar rats. Cancer Res 45, 194-197, 1985

Tessitore L, Bonelli G, Cecchini G, Amenta JS, Baccino FM. Regulation of protein turnover versus growth state: ascites hepatoma as a model for studies both in the animal and in vitro. Arch Biochem Biophys 255, 372-384, 1987.

Tracey KJ. The inflammatory reflex. Nature 420, 853-859, 2002.

Voss MJ, Entschladen F. Tumor interactions with soluble factors and the nervous system. Cell Commun Signal $8,21,2010$.

Wang L, Li JG, Jia BH, Wu YB, Zhou Q, Du ZH. [Protective effects of electric stimulation of vagus nerve on acute lung injury in rat with sepsis]. Zhongguo Wei Zhong Bing Ji Jiu Yi Xue 19, 593-595, 2007.

Yoshida T. Contributions of the ascites hepatoma to the concept of malignancy of cancer. Ann N Y Acad Sci 63, $852-881,1956$

Zhao CM, Hayakawa Y, Kodama Y, Muthupalani S, Westphalen CB, Andersen GT, Flatberg A, Johannessen H, Friedman RA, Renz BW, Sandvik AK, Beisvag V, Tomita H, Hara A, Quante M, Li Z, Gershon MD, Kaneko K, Fox JG, Wang TC, Chen D. Denervation suppresses gastric tumorigenesis. Sci Transl Med 6, 250ra115, 2014. 